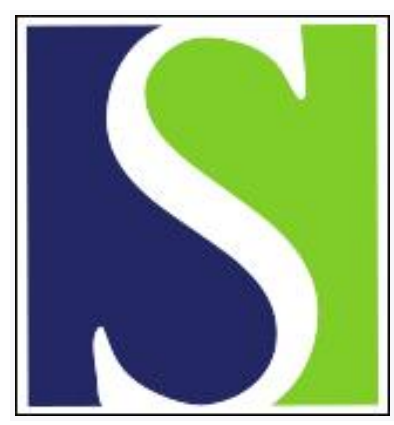

Scand J Work Environ Health 2000;26(6):461-469

https://doi.org/10.5271/sjweh.569

Issue date: Dec 2000

Cancer incidence among workers in six Norwegian aluminum plants

by Romundstad P, Andersen S, Haldorsen T

Key terms: bladder cancer; kidney cancer; lung cancer; pancreatic cancer; polycyclic aromatic hydrocarbon; primary aluminum production; Søderberg

This article in PubMed: www.ncbi.nlm.nih.gov/pubmed/11201392

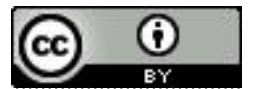




\title{
Cancer incidence among workers in six Norwegian aluminum plants
}

\author{
by Pål Romundstad, MSc, ${ }^{1,2}$ Aage Andersen, ${ }^{1}$ Tor Haldorsen, $M S c^{1}$
}

\author{
Romundstad $P$, Andersen $S$, Haldorsen T. Cancer incidence among workers in six Norwegian aluminum \\ plants. Scand J Work Environ Health 2000;26(6):461—469.
}

\begin{abstract}
Objectives This study investigated associations between exposure to polycyclic aromatic hydrocarbons (PAH) and the incidence of lung, bladder, kidney, and pancreatic cancer among Norwegian aluminum plant workers. Methods Cancer incidence was investigated from 1953 to 1996 among 11103 men employed for more than 3 years in the industry, giving 272554 person-years during follow-up. A job exposure matrix was constructed to estimate exposure to particulate $\mathrm{PAH}$ and fluorides. The observed cases of cancer were compared with expected figures calculated from national rates. Dose-response relations were investigated by internal comparisons using Poisson regression and stratified analyses for standardized incidence ratio. Potential confounding by smoking was investigated in subanalyses restricted to 3 of the plants.

Results The study showed an overall excess for bladder cancer, standardized incidence ratio 1.3 (95\% confidence interval 1.1-1.5), which increased with increasing cumulative exposure to PAH and reached a relative risk of about 2 for the upper exposure category in the analysis with 30 years of lag time. There was no association between cumulative PAH exposure and lung cancer, but there were indications of an elevated risk of kidney cancer among the most heavily PAH-exposed persons in the analyses with a lag time of 30 years. For pancreatic cancer we found a higher incidence among the PAH-exposed persons than among the unexposed ones, but no clear dose-response association was found.
\end{abstract}

Conclusions The study showed an association between bladder cancer and exposure to PAH, but gave no support to an association between PAH exposure and lung cancer in the primary aluminum industry.

Key lerms bladder cancer, kidney cancer, lung cancer, polycyclic aromatic hydrocarbons, pancreatic cancer, primary aluminum production, Søderberg.

Producing aluminum by the electrolysis of alumina leads to the release of a chemically complex mixture including both gases and particulates of varying chemical composition. Most attention has been focused on the effects of the particulate phase of the coal-tar-pitch volatiles (CTPV), principally because CTPV contain carcinogenic polycyclic aromatic hydrocarbons $(\mathrm{PAH})$ and other carcinogenic constituents (eg, arylamines and nitro$\mathrm{PAH})$.

The first epidemiologic report from the aluminum industry was published in 1971. It suggested that aluminum production workers were at an increased risk for lung cancer and possibly skin cancer (1). Since then, several studies have been published with varying results. An increased incidence of lung and bladder cancer was the most consistent finding, but an increased incidence of pancreatic, kidney, and hematopoietic and lymphatic cancer was also reported (2-6).

In 1984, the International Agency for Research on Cancer published an evaluation of cancer risk in this industry (7) and updated it in 1987 (8). The evaluations concluded that there is sufficient evidence that certain exposures during aluminum production cause cancer. Exposure to pitch volatiles in Søderberg departments was suggested as the causative agent, with lung and bladder as the main target organs.

Additional studies have been published, primarily in Canada and Norway, with a more thorough assessment of exposure and, in some of the studies, smoking habits accounted for $(9-14)$. In the Canadian studies,

1 The Cancer Registry of Norway, Oslo, Norway.

2 Institute of Environmental Medicine, Norwegian University of Science and Technology, Trondheim, Norway.

Reprint requests to: Pål Romundstad, The Cancer Registry of Norway, N-0310 Montebello, Oslo. Norway. [E-mail: pr@kreftregisteret.no] 
dose-response relations were found for bladder and lung cancer in terms of both length of employment in Søderberg potrooms and cumulative exposure to CTPV $(9,10)$. The Norwegian studies have shown inconsistent results. The first published report from Norway showed a significant elevated risk of lung cancer when local incidence rates were used for reference (3). More recent updates of the Norwegian cohorts, however, showed no elevated risk of lung cancer even among the most heavily PAH-exposed workers (12-14).

Limitations in study size have been a problem for the interpretation of the results in the Norwegian studies. The present study was initiated to clarify possible associations between PAH exposure and the incidence of lung, bladder, kidney, and pancreatic cancers in a combined update of all the Norwegian aluminum cohorts.

\section{Subjects and methods}

Aluminum is manufactured by the electrolysis of alumi$\mathrm{na}\left(\mathrm{Al}_{2} \mathrm{O}_{3}\right)$ dissolved in molten cryolite $\left(\mathrm{Na}_{3} \mathrm{AlF}_{6}\right)$ in several carbon-lined steel shells (pots). Alumina dust, solid fluoride salts, and hydrogen fluoride gas are emitted from

Table 1. Description of the contribution of person-years to the study and available PAH and fluoride measurements according to plant.

\begin{tabular}{|c|c|c|c|c|c|}
\hline \multirow[t]{2}{*}{ Plant } & \multirow[t]{2}{*}{$\begin{array}{l}\text { Person- } \\
\text { years }\end{array}$} & \multicolumn{2}{|c|}{$\begin{array}{l}\text { Available PAH } \\
\text { measurements }\end{array}$} & \multicolumn{2}{|c|}{$\begin{array}{l}\text { Available fluoride } \\
\text { measurements }\end{array}$} \\
\hline & & Area & Personal & Area & Personal \\
\hline Eydehavn & 21083 & - & - & 57 & 3 \\
\hline Ardal & 92094 & 50 & 731 & 4262 & 974 \\
\hline Sunndal & 51523 & 1810 & 1634 & 6772 & 1765 \\
\hline Mosiøen & 40464 & 2076 & 1840 & 2862 & 3226 \\
\hline Høyanger & 42020 & 400 & 636 & 1550 & 794 \\
\hline Tyssedal & 25370 & - & - & - & 25 \\
\hline Total cohort & 272554 & 4301 & 4841 & 15503 & 6815 \\
\hline
\end{tabular}

the pots, while the anodes liberate carbon monoxide and sulfur dioxide.

Two types of anodes are used for the production of aluminum. The Søderberg anode is regularly supplied with unbaked anode paste at the top, and the heat leads to emissions of CTPV from the paste. From prebaked anodes, on the contrary, only negligible amounts of particulate CTPV are emitted during electrolysis. Exposure to CTPV has also occurred in the carbon and anode departments where Søderberg paste and prebaked anodes are manufactured, but CTPV exposure in these departments has generally been lower than the exposures in Søderberg potrooms and has consisted of more volatile and presumably less carcinogenic substances (15).

Other exposures at aluminum smelters include heat, static magnetic fields, and some exposure to chrysotile asbestos. Exposure to asbestos has varied between smelters, but exposure has generally been low and primarily restricted to maintenance workers and pot liners.

The technology in the primary aluminum industry has changed from the use of open prebaked pots in the period from 1910 to about 1940, when Søderberg technology gradually took over. Since 1970 , the closed prebaked technology has gradually replaced the Søderberg technology.

Six Norwegian aluminum smelters were included in the present study (tables 1 and 2). Three of the smelters started operation before 1920 , and the remaining began in the period from 1947 to 1958.

Information on each employee was obtained from company records giving name, date of birth, departments of hire, job types, and dates for all job changes. Only workers employed for $>3$ years at an aluminum smelter were included in the study since we lacked precise information on job for some of those employed for $<3$ years. Since 1964 all inhabitants in Norway have had a unique identification number. These numbers were used for the linkage between data sources. Before 1964, the cohort was linked to the death and cancer registry data

Table 2. Description of the technology, period of operation, and reference to earlier studies of cancer incidence and follow-up periods of the earlier studies of cancer incidence according to plant. $(P A H=$ polycyclic aromatic hydrocarbons, VSS = vertical stud Søderberg, $\mathrm{HSS}=$ horisontal stud $\mathrm{S} ø$ derberg, $\mathrm{OPB}=$ open prebake, $\mathrm{CPB}=$ closed prebake, $\mathrm{CP}=$ carbon plant, $\mathrm{AP}=$ anode plant)

\begin{tabular}{|c|c|c|c|}
\hline $\begin{array}{l}\text { Plant and operation } \\
\text { period }\end{array}$ & $\begin{array}{l}\text { Development in technology } \\
\text { (calendar period of operation) }\end{array}$ & $\begin{array}{l}\text { Reference to earlier studies } \\
\text { of cancer incidence }\end{array}$ & Follow-up period \\
\hline Eydehavn, 1914--1975 & OPB $(1914-1975)$ & Andersen et al, $1982(3)$ & $1953-1979$ \\
\hline Årdal, $1947-$ & $\begin{array}{l}\text { AP \& CP }(1918-1975) \\
\text { HSS }(1948-1969), \text { OPB }(1959-1971) \\
\text { VSS }(1962-), \text { CPB }(1970-), C P(1949-), \text { AP }(1959-)\end{array}$ & $\begin{array}{l}\text { Rønneberg et al, } 1995(26) \\
\text { Andersen et al, } 1982(3) \\
\text { Rønneberg et al, } 1999(12)\end{array}$ & $\begin{array}{l}1953-1991 \\
1953-1979 \\
1953-1993\end{array}$ \\
\hline Sunndal, 1954- & $\begin{array}{l}\text { VSS }(1954-), \text { CPB (1969-) } \\
\text { CP }(1966-) \text {, AP (1968-) }\end{array}$ & $\begin{array}{l}\text { Andersen et al, } 1982(3) \\
\text { Romundstad et al, } 2000(13)\end{array}$ & $\begin{array}{l}1953-1979 \\
1953-1995\end{array}$ \\
\hline Mosjøen, 1958 & $\begin{array}{l}\text { VSS (1958), CPB (1988-) } \\
\text { CP }(1958-)\end{array}$ & $\begin{array}{l}\text { Andersen et al, } 1982(3) \\
\text { Romundstad et al, } 2000(13)\end{array}$ & $\begin{array}{l}1953-1979 \\
1953-1995\end{array}$ \\
\hline Høyanger, 1919- & $\begin{array}{l}\text { OPB }(1919-1941), \text { HSS }(1937-1978), \text { VSS }(1958-) \\
\text { CPB }(1981-), \text {, }\end{array}$ & Romundstad et al,2000 (14) & $1953-1995$ \\
\hline Tyssedal, 1915-1982 & $\begin{array}{l}\text { OPB }(1915-1950), \text { VSS }(1951-1982) \\
\text { VSS }(1951-1982)\end{array}$ & Andersen et al, $1982(3)$ & $1953-1979$ \\
\hline
\end{tabular}


by name and date of birth. Dates of death or emigration were found by linkage to the population register of Norway. Of the original 11397 men, 247 men (2.2\%) were not identified, and 47 were found to have died prior to the start of cancer registration in 1953. This left 11103 men for observation.

\section{Exposure assessment}

A job-exposure matrix covering all 6 plants was constructed to estimate individual exposure to total particulate PAH and total fluorides. Exposure was estimated quantitatively as the 8-hour time-weighted arithmetic averages. The fluoride measure also served as a proxy for total dust, sulfur dioxide, and carbon monoxide, as it was highly correlated with these exposures.

For 3 of the 6 plants (Sunndal, Mosjøen, and Høyanger) we used estimates from earlier studies $(13,14,16)$. At the Sunndal and Mosjøen plants, exposure to PAH and fluorides had been estimated from statistical modeling of industrial hygiene data and process data (16). At the Høyanger plant, the estimation was primarily based on the use of personal measurements, stationary measurements, and descriptions of changes in the process technology over time (14). For time periods with sufficient personal measurements $(N>5)$ the arithmetic mean was used as a direct measure of exposure for a job. Stationary measurements were used to indicate relative changes in periods lacking personal measurements. For periods with no measurements, exposure was assigned according to estimates from plants with similar technologies $(12-14,16$, 17). For the Ardal plant, exposure had been estimated earlier (12), but with a different assessment methodology and a different measure of exposure (geometric mean). In an attempt to secure a uniform approach, exposure was reassessed at this plant in a manner similar to that used at the Høyanger plant. At the plant in Eydehavn, exposure had been estimated earlier, but on a relative scale between 0 and 1 (17). These relative measures were transformed to quantitative measures by assigning a level of exposure to the highest exposed groups. The level assigned was based on measurements of fluorides sampled at the plant and from PAH measurements from similar departments in other plants $(12-14,16)$.

For the plant in Tyssedal, only a few measurements of total dust and fluorides had been sampled. Therefore we had to base our estimates of exposure at this plant on results from other plants with comparable technologies in the same time periods $(12-14,16,17)$. The number of available PAH and fluoride measurements for each plant is listed in table 1 . In table 3 we have listed the ranges of exposure estimates of PAH and fluorides for a few of the most important exposure groups over different calendar periods in an abridged form.
PAH estimates above $1000 \mu \mathrm{g} / \mathrm{m}^{3}$ were all related to stud pulling in vertical $\$ \varnothing$ derberg potrooms prior to 1985. The PAH exposure for other work categories in the Søderberg potrooms varied roughly between 100 and $500 \mu \mathrm{g} / \mathrm{m}^{3}$ before 1985 . Today the PAH exposure in $\mathrm{S} \phi$ derberg potrooms is considerably lower (generally $<20$ $\mu \mathrm{g} / \mathrm{m}^{3}$ ), mainly due to the implementation of dry-anode technology and the use of closed cabins when stud pulling and flex raising are performed.

Maintenance personnel working in the process departments were assigned one-third of the average exposure estimated for the corresponding process workers based on estimates of time spent by the maintenance workers in the same departments.

Cumulative exposure was used as an indicator of individual dose and calculated for each person-year under observation as the product of the exposure intensity and duration summed for all jobs held. In the analyses "unexposed" person-time constituted 1 exposure category, and the remaining exposed person-years were allocated into 3 exposure categories according to the number of expected cases in each exposure category. Potential induction and latency periods were investigated by lagging exposure for $0,10,20$, and 30 years $(18,19)$. A lag time of 20 years meant that exposure during the last 20 years prior to each year of observation was disregarded.

Due to uncertainties in the quantitative exposure estimates for the periods before 1970, we performed some additional analyses using the time (in years) employed

Table 3. Ranges of exposure estimates of polycyclic aromatic hydrocarbons (PAH) and fluorides for selected exposure groups by calendar period.

\begin{tabular}{|c|c|c|}
\hline Department & $\begin{array}{l}\text { Range of PAH } \\
\text { estimates }\left(\mu \mathrm{g} / \mathrm{m}^{3}\right)\end{array}$ & $\begin{array}{l}\text { Range of fluoride } \\
\text { estimates }\left(\mathrm{mg} / \mathrm{m}^{3}\right)\end{array}$ \\
\hline \multicolumn{3}{|c|}{ Open prebaked (OPB) } \\
\hline \multicolumn{3}{|l|}{ Pot operator } \\
\hline $1913-1964$ & $0-50$ & $1.9-2.5$ \\
\hline $1965-1975$ & $0-50$ & $1.3-2.2$ \\
\hline \multicolumn{3}{|c|}{ HS-Søderberg (HSS) } \\
\hline \multicolumn{3}{|l|}{ Pot operator } \\
\hline $1939-1978$ & $100-300$ & $1.5-2.5$ \\
\hline \multicolumn{3}{|c|}{ VS-Søderberg (VSS) } \\
\hline \multicolumn{3}{|l|}{ Pot operator } \\
\hline $1951-1979$ & $55-400$ & $0.4-2.5$ \\
\hline $1980-1987$ & $25-110$ & $0.3-1.0$ \\
\hline $1988-1996$ & $5--25$ & $0.1-0.5$ \\
\hline \multicolumn{3}{|l|}{ Stud puller } \\
\hline $1951-1984$ & $370-3400$ & $0.5-1.7$ \\
\hline $1985-1996$ & $5-100$ & $0.1-0.6$ \\
\hline \multicolumn{3}{|c|}{ Closed prebaked (CPB) } \\
\hline \multicolumn{3}{|c|}{ Pot operator } \\
\hline $1969-1996$ & $0-10$ & $0.1-1.0$ \\
\hline \multicolumn{3}{|l|}{ Anode production } \\
\hline $1918-1979$ & $25--200$ & $0-0.3$ \\
\hline $1980-1996$ & $5-100$ & $0-0.3$ \\
\hline \multicolumn{3}{|l|}{ Potlining } \\
\hline $1913-1996$ & $5-200$ & $0.1-2.0$ \\
\hline
\end{tabular}

Scand J Work Environ Health 2000, vol 26, no 6 
in departments with PAH exposure and years of employment in Søderberg potrooms as alternative dose measures.

\section{Smoking}

We had information on individual smoking habits from 3 of the 6 plants. The smoking habits were abstracted from medical files at the health departments of these smelters and supplemented with information from longterm employees. The smoking habits had been sampled in the time period from about 1960 to 1997 , and the duration and amount smoked were mainly unknown. The data were therefore categorized into never, current, and former smokers, and persons with unknown smoking status. Smoking status was determined for $46 \%$ of the total cohort and for $85 \%$ of the workers at the 3 plants for which smoking data was accessible. Of the 5107 workers with smoking data, $24 \%$ were never smokers, $55 \%$ were current smokers, and $21 \%$ were former smokers. Due to the lack of information on smoking cessation among the former smokers, they were treated as former smokers throughout the analyses.

\section{Analysis of cancer incidence}

Because of the inclusion criteria of 3 years of employment, the follow-up of cancer incidence started after 3

Table 4. Observed and expected numbers of different types of cancer among 11103 male Norwegian aluminum smelter workers in the follow-up period from 1953 to 1996, accompanied by the standardized incidence ratio (SIR). $(95 \% \mathrm{Cl}=95 \%$ confidence interval)

\begin{tabular}{lrrrr}
\hline Cancer site $^{\text {a }}$ & $\begin{array}{r}\text { Observed } \\
(\mathrm{N})\end{array}$ & $\begin{array}{r}\text { Expected } \\
(\mathrm{N})\end{array}$ & SIR & $95 \% \mathrm{CI}$ \\
\hline All sites (140-204) & 1503 & 1453.8 & 1.0 & $1.0-1.1$ \\
Upper respiratory (141,143-8, 161) & 41 & 44.7 & 0.9 & $0.6-1.1$ \\
Lip (140) & 20 & 18.5 & 1.1 & $0.7-1.7$ \\
Esophagus (150) & 11 & 17.7 & 0.6 & $0.3-1.1$ \\
Stomach (151) & 122 & 119.8 & 1.0 & $0.9-1.2$ \\
Colon (153) & 126 & 119.9 & 1.1 & $0.9-1.3$ \\
Rectum (154) & 86 & 76.4 & 1.1 & $0.9-1.4$ \\
Liver (155.0) & 1 & 9.7 & 1.0 & $0.5-1.9$ \\
Pancreas (157) & 46 & 49.5 & 0.9 & $0.7-1.2$ \\
Larynx (161) & 24 & 18.4 & 1.3 & $0.8-1.9$ \\
Lung (162, exclusive of 162.2) & 189 & 183.1 & 1.0 & $0.9-1.2$ \\
Pleura (162.2) & 1 & 5.2 & 0.2 & $0.0-1.1$ \\
Prostate (177) & 305 & 275.9 & 1.1 & $1.0-1.2$ \\
Testes (178) & 17 & 20.3 & 0.8 & $0.5-1.3$ \\
Kidney (180) & 55 & 52.2 & 1.1 & $0.8-1.4$ \\
Bladder (181) & 130 & 101.7 & 1.3 & $1.1-1.5$ \\
Malignant melanoma(190) & 25 & 49.8 & 0.5 & $0.3-0.7$ \\
Other skin (191) & 48 & 50.3 & 1.0 & $0.7-1.3$ \\
Brain/Nervous system(193) & 33 & 39.0 & 0.9 & $0.6-1.2$ \\
Thyroid (194) & 11 & 7.8 & 1.4 & $0.7-2.5$ \\
Unspecified (199) & 67 & 57.4 & 1.2 & $0.9-1.5$ \\
Hodgkin's lymphoma(201) & 10 & 9.5 & 1.1 & $0.5-1.9$ \\
Non-Hodgkin's lymphoma (200, 202) & 35 & 39.6 & 0.9 & $0.6-1.2$ \\
Multiple myeloma(203) & 33 & 24.5 & 1.4 & $0.9-1.9$ \\
Leukemia (204) & 36 & 34.5 & 1.0 & $0.7-1.4$ \\
All other sites & 46 & 47.0 & 1.0 & $0.7-1.3$ \\
\hline I. & & & & \\
\hline
\end{tabular}

a Codes of the International Classification of Diseases, 7 th revision, in parentheses. years of employment (net employment time) or from 1 January 1953 if the 3-year date of employment was reached before that date. Observation continued until 31 December 1996 or to the time of death or emigration. The cohort contributed 272554 person-years at risk to the study.

From 1953 on, the Cancer Registry of Norway has had complete coverage of all incident cancers in the total population except basal-cell carcinoma of the skin, which was omitted in the present analysis. The registration system has been built on multiple reporting from pathological laboratories and hospital departments with compulsory reporting from physicians. The coding of cancers was based on a modified version of the 7 th revision of the International Classification of Diseases. Standardized incidence ratios (SIR) were calculated as ratios between the observed and the expected numbers of cancer cases, the latter having been calculated from national incidence rates in 5-year periods by 5 -year age groups. In an additional analysis of lung and bladder cancer we also used the local county incidence rates to calculate the expected values. The $95 \%$ confidence intervals $(95 \% \mathrm{Cl})$ were calculated on the assumption of a Poisson distribution of the observed numbers.

Poisson regression analysis was used to determine the internal dose-response relations and for the exploration of potential confounding from smoking. Age was included in the models in 6 age groups $(<55,55-64,65-69$, $70-74,75-79, \geq 80$ years), and period of diagnosis was included in 3 calendar periods (1953-1970, 19711984, 1985-1996). To investigate potential residual confounding due to the relatively wide age intervals, we performed sensitivity analyses using 8 and 10 age groups to evaluate possible effects on the effect estimates. We also performed supplementary analyses with indicator variables for plants to investigate potential confounding by factors related to region of residence.

Trend tests for the investigation of potential dose-response relations were performed by assigning scores (14) or applying the arithmetic mean of cumulative $\mathrm{PAH}$ exposure ("PAH dose") to the exposure categories. Correlation coefficients between exposure to $\mathrm{PAH}$ and fluorides were calculated by weighting the person-years through follow-up.

The calculations of the SIR values and the Poisson regression analyses were performed with the program package EPICURE (20).

\section{Results}

The total number of observed cancers $(\mathrm{N}=1503)$ was close to the expected ( $N=1454)$, calculated from national rates giving an overall SIR of 1.03 (table 4). Urinary bladder cancer was in excess, with an SIR of $1.3(95 \%$ 
CI 1.1-1.5) based on 130 cases, while the observed numbers of lung, kidney, and pancreatic cancers were close to the expected figures. Malignant melanoma was in deficit with an SIR of $0.5(95 \% \mathrm{CI} 0.3-0.7)$. Only 1 case of mesothelioma was observed versus 5 expected.

The incidence of bladder cancer increased with increasing cumulative exposure to PAH and with increasing lag times for the upper exposure category (table 5). The SIR analysis of bladder cancer incidence and PAH exposure showed essentially the same "dose"-response patterns as the Poisson regression analysis.

We found no association between cumulative exposure to PAH and lung cancer in the internal regression analysis (table 5) or in the SIR analysis (results not shown). Nor did the analyses suggest a dose-response association between exposure to PAH and pancreatic cancer (table 5). Although the analyses indicated an increased incidence of pancreatic cancer among the PAHexposed persons when compared with the unexposed ones, the trend among the exposed was unclear, and the apparent excess could be explained by a deficit among the unexposed, the SIR values varying from 0.4 to 0.9 among the unexposed (table 5). Both the SIR analyses (results not shown) and the internal regression analyses on kidney cancer risk indicated an association with cumulative PAH exposure when exposure was lagged by $\geq 20$ years (table 5 ).
In the subanalyses restricted to those with known smoking habits, there were no indications of substantial confounding by smoking (table 6).

The analyses using time employed in departments with PAH exposure, or employment time in Søderberg potrooms, showed essentially the same results for bladder cancer as the analyses using the quantitative $\mathrm{PAH}$ exposure measure for lag times of $\leq 20$ years (results not shown). When a lag time of 30 years was used in the analysis, the associations between employment time in these departments and bladder cancer diminished. We found no association between duration of employment in these departments and the incidence of lung cancer (results not shown).

When using the cumulative fluoride exposure measure, we only found a weak association with the incidence of bladder cancer for lag times of $<20$ years, possibly due to a correlation between the fluoride and PAH exposure measures (correlation coefficient $0.60-0.66$ in the different lag-time analyses). Cumulative exposure to fluorides showed little evidence of associations with cancers of the kidney, pancreas, or lung in the analyses.

\section{Discussion}

Our study is among the largest studies of aluminum production workers, with almost 50 years of follow-up,

Table 5. Poisson regression analysis of bladder, lung, kidney, and pancreatic cancer risk (rate ratio) by cumulative exposure to polycyclic aromatic hydrocarbons (PAH), as lagged by 0,20 and 30 years and controlled for age and calendar period. $(95 \% \mathrm{Cl}=95 \%$ confidence interval, Ref = reference category)

\begin{tabular}{|c|c|c|c|c|c|c|c|c|c|c|c|c|}
\hline \multirow[b]{2}{*}{ Lag time } & \multicolumn{3}{|c|}{ Bladder cancer } & \multicolumn{3}{|c|}{ Lung cancer } & \multicolumn{3}{|c|}{ Pancreatic cancer } & \multicolumn{3}{|c|}{ Kidney cancer } \\
\hline & $\begin{array}{l}\text { Cases } \\
\text { (N) }\end{array}$ & $\begin{array}{l}\text { Rate } \\
\text { ratio }\end{array}$ & $95 \% \mathrm{Cl}$ & $\begin{array}{l}\text { Cases } \\
\text { (N) }\end{array}$ & $\begin{array}{l}\text { Rate } \\
\text { ratio }\end{array}$ & $95 \% \mathrm{Cl}$ & $\begin{array}{c}\text { Cases } \\
(\mathrm{N})\end{array}$ & $\begin{array}{l}\text { Rate } \\
\text { ratio }\end{array}$ & $95 \% \mathrm{Cl}$ & $\begin{array}{c}\text { Cases } \\
(\mathrm{N})\end{array}$ & $\begin{array}{l}\text { Rate } \\
\text { ratio }\end{array}$ & $95 \% \mathrm{Cl}$ \\
\hline \multicolumn{13}{|l|}{0 years } \\
\hline $\begin{array}{l}0 \mu \mathrm{g} / \mathrm{m}^{3} \cdot \text { years } \\
0.1-499 \mu \mathrm{g} / \mathrm{m}^{3} \cdot \text { years } \\
500-1999 \mu \mathrm{g} / \mathrm{m}^{3} \cdot \text { years } \\
\geq 2000 \mu \mathrm{g} / \mathrm{m}^{3} \cdot \text { years }\end{array}$ & $\begin{array}{l}38 \\
22 \\
29 \\
41\end{array}$ & $\begin{array}{l}1.0 \\
1.3 \\
1.3 \\
1.6\end{array}$ & $\begin{array}{l}\text { Ref } \\
0.7-2.1 \\
0.8-2.1 \\
1.0-2.4\end{array}$ & $\begin{array}{l}66 \\
36 \\
42 \\
45\end{array}$ & $\begin{array}{l}1.0 \\
1.1 \\
1.1 \\
1.0\end{array}$ & $\begin{array}{l}\text { Ref } \\
0.7-1.7 \\
0.7-1.6 \\
0.7-1.4\end{array}$ & $\begin{array}{r}10 \\
8 \\
5 \\
13\end{array}$ & $\begin{array}{l}1.0 \\
1.7 \\
2.5 \\
1.9\end{array}$ & $\begin{array}{l}\text { Ref } \\
0.6-4.3 \\
1.1-5.6 \\
0.8-4.3\end{array}$ & $\begin{array}{r}20 \\
8 \\
12 \\
15\end{array}$ & $\begin{array}{l}1.0 \\
0.8 \\
1.0 \\
1.1\end{array}$ & $\begin{array}{l}\text { Ref } \\
0.3-1.8 \\
0.5-2.0 \\
0.6-2.1\end{array}$ \\
\hline $\begin{array}{l}\text { Trend test } \\
\text { Scores }(1,2,3,4) \\
\text { Mean PAH dose }\end{array}$ & & & $\begin{array}{l}\text { P-value } \\
0.05 \\
0.08\end{array}$ & & & $\begin{array}{l}\text { P-value } \\
>0.5 \\
>0.5\end{array}$ & & & $\begin{array}{l}\text { P-value } \\
0.08 \\
0.4\end{array}$ & & & $\begin{array}{l}\text { P-value } \\
>0.5 \\
>0.5\end{array}$ \\
\hline \multicolumn{13}{|l|}{20 years } \\
\hline $\begin{array}{l}0 \mu \mathrm{g} / \mathrm{m}^{3} \cdot \text { years } \\
0-499 \mu \mathrm{g} / \mathrm{m}^{3} \cdot \text { years } \\
500-1999 \mu \mathrm{g} / \mathrm{m}^{3} \cdot \text { years } \\
\geq 2000 \mu \mathrm{g} / \mathrm{m}^{3} \cdot \text { years }\end{array}$ & $\begin{array}{l}52 \\
20 \\
27 \\
31\end{array}$ & $\begin{array}{l}1.0 \\
1.3 \\
1.3 \\
1.8\end{array}$ & $\begin{array}{l}\text { Ref } \\
0.8-2.1 \\
0.8-1.9 \\
1.1-2.8\end{array}$ & $\begin{array}{l}93 \\
38 \\
30 \\
28\end{array}$ & $\begin{array}{l}1.0 \\
1.4 \\
0.9 \\
1.0\end{array}$ & $\begin{array}{l}\text { Ref } \\
0.9-2.0 \\
0.6-1.3 \\
0.6-1.5\end{array}$ & $\begin{array}{r}12 \\
15 \\
10 \\
9\end{array}$ & $\begin{array}{l}1.0 \\
4.5 \\
2.4 \\
2.8\end{array}$ & $\begin{array}{l}\text { Ref } \\
2.1-9.9 \\
1.0-5.8 \\
1.1-7.1\end{array}$ & $\begin{array}{r}26 \\
8 \\
9 \\
12\end{array}$ & $\begin{array}{l}1.0 \\
1.2 \\
1.1 \\
1.9\end{array}$ & $\begin{array}{l}\text { Ref } \\
0.5-2.6 \\
0.5-2.3 \\
0.9-4.0\end{array}$ \\
\hline $\begin{array}{l}\text { Trend test } \\
\text { Scores }(1,2,3,4) \\
\text { Mean PAH dose }\end{array}$ & & & $\begin{array}{l}\text { P-value } \\
0.02 \\
0.04\end{array}$ & & & $\begin{array}{l}\text { P-value } \\
>0.5 \\
0.3\end{array}$ & & & $\begin{array}{l}\text { P-value } \\
0.03 \\
0.3\end{array}$ & & & $\begin{array}{l}\text { P-value } \\
0.2 \\
0.07\end{array}$ \\
\hline \multicolumn{13}{|l|}{30 years } \\
\hline $\begin{array}{l}0 \mu \mathrm{g} / \mathrm{m}^{3} \cdot \text { years } \\
0-499 \mu \mathrm{g} / \mathrm{m}^{3} \cdot \text { years } \\
500-1999 \mu \mathrm{g} / \mathrm{m}^{3} \cdot \text { years } \\
\geq 2000 \mu \mathrm{g} / \mathrm{m}^{3} \cdot \text { years }\end{array}$ & $\begin{array}{l}75 \\
15 \\
22 \\
18\end{array}$ & $\begin{array}{l}1.0 \\
1.0 \\
1.3 \\
2.0\end{array}$ & $\begin{array}{l}\text { Ref } \\
0.7-1.9 \\
0.8-2.0 \\
1.1-3.4\end{array}$ & $\begin{array}{r}130 \\
23 \\
30 \\
6\end{array}$ & $\begin{array}{l}1.0 \\
1.0 \\
1.1 \\
0.4\end{array}$ & $\begin{array}{l}\text { Ref } \\
0.6-1.6 \\
0.7-1.7 \\
0.2-1.0\end{array}$ & $\begin{array}{r}29 \\
5 \\
8 \\
4\end{array}$ & $\begin{array}{l}1.0 \\
1.0 \\
1.4 \\
1.5\end{array}$ & $\begin{array}{l}\text { Ref } \\
0.4-2.7 \\
0.6-3.3 \\
0.5-4.6\end{array}$ & $\begin{array}{r}33 \\
7 \\
9 \\
6\end{array}$ & $\begin{array}{l}1.0 \\
1.3 \\
2.0 \\
2.8\end{array}$ & $\begin{array}{l}\text { Ref } \\
0.5-3.3 \\
0.9-4.3 \\
1.1-7.4\end{array}$ \\
\hline $\begin{array}{l}\text { Trend test } \\
\text { Scores }(1,2,3,4) \\
\text { Mean PAH dose }\end{array}$ & & & $\begin{array}{l}\text { P-value } \\
0.03 \\
0.003\end{array}$ & & & $\begin{array}{l}\text { P-value } \\
0.3 \\
0.07\end{array}$ & & & $\begin{array}{l}\text { P-value } \\
0.3 \\
0.4\end{array}$ & & & $\begin{array}{l}\text { P-value } \\
0.02 \\
0.05\end{array}$ \\
\hline
\end{tabular}

${ }^{a}$ The arithmetic mean cumulative exposure in each exposure group was used. 
Table 6. Subanalyses of lung and bladder cancer risk with restriction to those with known smoking habits (Poisson regression) by smoking status and cumulative exposure to polycyclic aromatic hydrocarbons (PAH) lagged by 20 and 30 years, respectively, and controlled for age and calendar period. (95\% $\mathrm{Cl}=95 \%$ confidence interval, Ref $=$ reference category)

\begin{tabular}{|c|c|c|c|c|c|c|c|c|c|c|}
\hline & \multicolumn{5}{|c|}{ Lung cancer } & \multicolumn{5}{|c|}{ Bladder cancer } \\
\hline & \multirow[b]{2}{*}{ Cases (N) } & \multicolumn{2}{|c|}{ Smoking included } & \multicolumn{2}{|c|}{ Smoking not included } & \multirow[b]{2}{*}{ Cases (N) } & \multirow{2}{*}{\multicolumn{2}{|c|}{$\frac{\text { Smoking included }}{\text { Rate ratio } 95 \% \mathrm{Cl}}$}} & \multicolumn{2}{|c|}{ Smoking not included } \\
\hline & & Rate ratio & $95 \% \mathrm{Cl}$ & Rate ratio & $95 \% \mathrm{Cl}$ & & & & Rate ratio & $95 \% \mathrm{Cl}$ \\
\hline \multicolumn{11}{|l|}{ Smoking status } \\
\hline Never & 1 & 1.0 & Ref & . & . & 2 & 1.0 & Ref & . & \\
\hline Former & 5 & 3.4 & $0.4-29.6$ & . & . & 16 & 5.1 & $1.2-70$ & . & \\
\hline Current & 59 & 21.0 & $2.9-151$ & . & . & 33 & 5.6 & $1.3-23.2$ & . & \\
\hline \multicolumn{11}{|l|}{ Cumulative PAH exposure } \\
\hline $0 \mu \mathrm{g} / \mathrm{m}^{3} \cdot$ years & 18 & 1.0 & $\operatorname{Ref}$ & 1.0 & Ref & 29 & 1.0 & Ref & 1.0 & Ref \\
\hline $0.1-499 \mu \mathrm{g} / \mathrm{m}^{3}$. years & 14 & 1.7 & $0.9-3.1$ & 1.9 & $1.0-3.4$ & 5 & 0.8 & $0.3-2.2$ & 0.9 & $0.3-2.3$ \\
\hline $500-1999 \mu \mathrm{g} / \mathrm{m}^{3} \cdot$ years & 22 & 1.1 & $0.6-2.1$ & 1.1 & $0.6-2.2$ & 8 & 1.1 & $0.5-2.4$ & 1.1 & $0.5-2.5$ \\
\hline$\geq 2000 \mu \mathrm{g} / \mathrm{m}^{3} \cdot$ years & 7 & 0.3 & $0.1-0.9$ & 0.3 & $0.1-1.0$ & 9 & 2.6 & $1.1-5.9$ & 2.8 & $1.2-6.4$ \\
\hline Trend test & & & P-value & & P-value & & & P-value & & P-value \\
\hline Scores $(1,2,3,4)$ & & & 0.1 & & 0.2 & & & 0.09 & & 0.06 \\
\hline Mean dose & & & 0.02 & & 0.03 & & & 0.001 & & 0.003 \\
\hline
\end{tabular}

a The arithmetic mean cumulative exposure in each exposure group was used.

272554 person-years, and over 1500 incident cases of cancer. The results showed an association between exposure to PAH and bladder cancer. No positive association was observed between cumulative exposure to $\mathrm{PAH}$ and the risk of lung cancer.

\section{Lung cancer}

The lack of a positive association between PAH exposure and lung cancer in the present study is in contrast to the results of a Canadian study, which showed an association between lung cancer mortality and exposure to CTPV or work in Søderberg departments, on the basis of 338 lung cancer deaths (10). Other investigations of lung cancer among primary aluminum workers have shown conflicting results $(4,6,11)$.

PAH has been established as one of the most significant groups of lung carcinogens in various industrial and environmental settings (21). As exposure to PAH in the S $\varnothing$ derberg departments far exceeded exposures in many other workplaces, with the possible exception of gas and coke works (22), a positive association with lung cancer was to be expected also in this study. Differences in duration, level, and chemical composition of exposure may in part explain the conflicting findings. The estimates of PAH exposure in the Norwegian plants were somewhat lower than the exposure estimated in the Canadian study (10), when a PAH content of benzene-soluble material (BSM) of about $20 \%$ or a benz(a)pyrene content of about $5 \%$ in PAH was assumed. Furthermore, the workers in the Canadian studies seemed to have been employed for longer periods in "PAH-exposed jobs" than the workers in our study (on the average). This difference is reflected by the lower "dose" estimates in our study than in the Canadian study (10). The upper exposure category in our study was restricted downwards by $2000 \mu \mathrm{g} / \mathrm{m}^{3} \mathrm{PAH}$ years or approximately $10 \mathrm{mg} / \mathrm{m}^{3} \mathrm{BSM}$-years. In the Canadian study the upper-exposure category was restricted downwards by $30 \mathrm{mg} / \mathrm{m}^{3}$ BSM-years (10). However, as we found no indications of an elevated risk of lung cancer, even among workers with $>20$ years in jobs with high $\mathrm{PAH}$ exposure, differences in the duration of exposure are not a likely explanation for the discrepancy. Furthermore, the increased risk of lung cancer in the Canadian study appeared to be present already for the 3rd exposure group, which was restricted downwards by 10 $\mathrm{mg} / \mathrm{m}^{3}$ BSM-years.

The rate of lung cancer is considerably higher in Canada than in Norway, while the incidence of bladder cancer is similar $(23,24)$. It is, therefore, also possible that part of the inconsistency may be related to differences in historical smoking habits and diet between the populations (14).

Asbestos has been mentioned as a potential confounder in studies of lung cancer among aluminum workers (10). However, as the exposure to asbestos at these plants in general has been low, and there was also a deficit of mesotheliomas in our study, negative confounding from asbestos exposure seemed unlikely.

The first Norwegian study of aluminum workers reported an elevated risk of lung cancer (3). Still, later studies have been published that have not confirmed an elevated risk of lung cancer. Nor have they indicated any association between PAH exposure and lung cancer $(12-14)$. The excess risk found in the first study could mainly be attributed to workers employed for $<4$ years and to plants situated in counties with low local rates of lung cancer.

A methodological problem in studies of this type is the choice of an external reference population for the es- 
timation of expected rates. When we used local county rates instead of national rates, the overall SIR for lung cancer increased from 1.0 to 1.4 , while the overall SIR for bladder cancer only showed a modest increment, from 1.3 to 1.4 (table 7). The comparison of industrial workers in small industrial communities with local rates, dominated by surrounding farming, fishing and forestry communities, is, however, probably just as questionable as the use of national rates. As the use of Norwegian national rates has the advantage of robustness when compared with the more unstable local rates, the national rates were our primary choice for the SIR analyses. This use may have biased the overall SIR of lung cancer downwards. Still, it should not have affected the doseresponse evaluations, as the additional internal analysis including plant as an indicator variable for regional residence did not alter the effect estimates. In our study internal analysis was regarded to be the most important factor in the evaluation of possible associations and causal risk, and more attention has been focused on dose-response evaluations than on overall incidence rates in the cohort when compared with an external reference population.

\section{Urinary tract cancers}

Although clearly present, the association between PAH exposure and bladder cancer in our study was weaker than in a Canadian case-referent study (9), which reported a clear increase in the smoking-adjusted OR (odds ratio) with increasing cumulative benz(a)pyrene or BSM exposure when based on 138 cases of bladder cancer. The risk also increased with increasing years of employment in Søderberg potrooms, reaching 5.2 (95\% CI 3.1-8.8) after $>20$ years of exposure (9). Another Canadian study has also found associations between bladder cancer and CTPV exposure (11). In summary these studies strongly support a causal factor being present in the Søderberg departments of aluminum smelters. However, identification of such causal factor(s) is difficult. It seems practically impossible with epidemiologic methods to disentangle the risk posed by individual PAH or related compounds in CTPV, principally because the substances always occur in mixtures and because they are often adsorbed on particles of different size and origin. It has been proposed that the true cause might be found among the minor components of CTPV, such as aromatic amines and nitro-PAH, which are known or suspected bladder carcinogens (9).

Fluoride exposure has also been implicated as a potential bladder carcinogen (25). However, in most studies, the risk of bladder cancer seems to be more related to work in Søderberg potrooms than to work in prebaked potrooms $(9,26)$, the main difference between the potrooms being CTPV exposure and not exposure to fluorides.
Table 7. Observed and expected cases of lung and bladder cancer and thestandardized incidence ratio $(S \mid R)$ by use of national or local county reference rates. $(95 \% \mathrm{Cl}=95 \%$ confidence interval)

\begin{tabular}{|c|c|c|c|c|c|c|c|}
\hline \multirow[b]{2}{*}{$\begin{array}{l}\text { Type } \\
\text { of } \\
\text { cancer }\end{array}$} & \multirow[b]{2}{*}{$\begin{array}{l}\text { Observed } \\
\text { (N) }\end{array}$} & \multicolumn{3}{|c|}{ Use of national rates } & \multicolumn{3}{|c|}{ Use of local rates ${ }^{b}$} \\
\hline & & $\begin{array}{l}\text { Ex- } \\
\text { pected } \\
\text { (N) }\end{array}$ & SIR & $95 \% \mathrm{Cl}$ & $\begin{array}{l}\text { Ex- } \\
\text { pected } \\
\text { (N) }\end{array}$ & SIR & $95 \% \mathrm{Cl}$ \\
\hline Lung & 189 & 183.1 & 1.0 & $0.9-1.2$ & 139.6 & 1.4 & $1.2-1.6$ \\
\hline Bladder & 130 & 101.7 & 1.3 & $1.1-$ & 92.5 & 1.4 & $1.2-1.7$ \\
\hline
\end{tabular}

It has been suggested that the heat exposure experienced by these workers may be a co-factor in the development of urinary tract cancer (27). Exposure to heat leads to dehydration, which in turn may lead to prolonged retention of concentrated urine containing carcinogens (28). Recently a large prospective study has shown a decreased risk of bladder cancer in association with high fluid intake, and the finding lends some support to this hypothesis (29).

The results on PAH exposure and kidney cancer in our study were difficult to evaluate (table 5). There seemed to be a trend toward a lag time of 30 years. Previous studies of this industry have also shown increased risks of kidney cancer $(2,4,26)$, but in these studies the risk seemed less related to PAH exposure. However, as our study has the advantage of using incidence data, as compared with the use of mortality data in most previous investigations, the results obtained may warrant further investigation. The bladder and kidney may share some common risk factors for CTPV that might be of less importance for lung cancer risk.

\section{Other types of cancers}

Several studies have indicated an elevated risk for pancreatic cancer among aluminum plant workers, including 2 recent Norwegian studies that indicated an association between PAH exposure and pancreatic cancer (4, 12,13 ). The findings have, however, been based on few cases, and, in the 2 Norwegian studies, the association could partly be explained by a deficit of cases among the unexposed group. On the basis of the unclear findings in our combined study, we believe that the evidence of an association between PAH exposure and pancreatic cancer among Norwegian aluminum workers is weak.

The deficit of malignant melanomas observed in the present study may be related to less sun exposure in association with socioeconomic status (recreational habits) and geographic residence. Five of the plants with a deficit of malignant melanomas were situated in narrow valleys surrounded by tall mountains on the west coast of 
Norway, while a single plant (Eydehavn) with elevated rates was situated in the southern part of Norway. There is a large variation in the incidence of malignant melanoma in Norway, the incidence doubling from the north to the south.

\section{Residual confounding by age}

The sensitivity analysis investigating potential residual confounding by age indicated that the 6 age groups used by us were probably sufficient to control for age in the internal analysis since the inclusion of additional age groups had minor impact on the effect estimates.

\section{Exposure}

Despite a substantial number of measurements, the estimation of exposure was inevitably encumbered with considerable uncertainty, particularly in the period before 1970, and for the plants with few measurements. Furthermore, no account was taken of the use of respiratory protection or the potential dermal uptake of PAH. The use of cumulative PAH exposure as a dose measure should be viewed as a surrogate since the potential etiologic agent(s) in CTPV is unknown. In addition, differences in the qualitative composition of the coal tar pitch and the different bioavailability of various forms of PAH (adsorbance on particles) may be of importance. Thus nondifferential misclassification of exposure is a potential threat to the study, as it may lead to the attenuation of dose-response associations and to reduced power. However, misclassification probably does not explain the lack of association between lung cancer and PAH exposure. The size of our study, the additional investigation using alternative exposure indicators, and the use of internal analyses all add credibility to the observed lack of association. Furthermore, we believe that the precision of our exposure estimates compares favorably with those of most retrospective epidemiologic studies.

\section{Smoking habits}

Although the smoking variable was crude, the wellknown associations between cancer of the lung and bladder and smoking habits were observed in the subanalyses. The relative risk for lung cancer among smokers, when compared with never smokers, was estimated to be about 20 in this study, and it was compatible with risk found in other studies. Since the internal regression analyses showed only minor changes in the effect estimates after control for smoking, one could probably exclude smoking as a major confounder in our study. However, the lack of association for lung cancer and the weaker association found for bladder cancer, in comparison with the corresponding results of the Canadian studies, may still be partially caused by general differences in smoking habits. The mean number of cigarettes smoked a day by our cohort varied roughly between 7 and 15 between the plants while the respective mean in one of the Canadian studies (10) was reported to be 18 cigarettes a day (average value for referents).

\section{Concluding remarks}

The robustness and results of our study add further evidence to the established association between bladder cancer and exposure to CTPV in the aluminum industry. The most important etiologic agents for bladder cancer probably derive from CTPV (eg, particulate $\mathrm{PAH}$, nitro-PAH, or arylamines) which are released during the use of Søderberg anodes and, to a less degree, during the manufacture of anode material in the carbon and anode departments. The generally held view of an association between PAH exposure and lung cancer in the aluminum industry was, however, not supported.

\section{Acknowledgments}

This work was part of a project supported by grants from The Nordic Aluminum Industry's Secretariat for Health, Environment and Safety and the Work Environment Fund of the Confederation of Norwegian Business and Industry.

We acknowledge the support from project committee members Erle Grieg Astrup, Arvid Bastiansen, Bjørn Hilt, Sverre Langård, Eirik Nordheim, Odd Arnold Hauge, and Per Iver Øksne. We thank Jan Ivar Martinsen for his valuable help with the programming and data analyses. Alf Rønneberg started, planned, and participated in the early phases of this project. He died in 1997.

\section{References}

1. Konstantinov VG, Kuzminykh AI. Tarry substances and 3,4benzpyrene in the air of electrolytic shops of aluminium works and their carcinogenic significance [in Russian]. Hyg Sanit 1971;36:368-71.

2. Gibbs GW. Mortality of aluminum reduction plant workers, 1950 through 1977. J Occup Med 1985;27:761-70.

3. Andersen A, Dahlberg BE, Magnus K, Wannag A. Risk of cancer in the Norwegian aluminum industry. Int $\mathrm{J}$ Cancer 1982;29:295-8.

4. Rockette HE, Arena VC. Mortality studies of aluminum reduction plant workers: potroom and carbon department. J Occup Med 1983;25:549-57. 
5. Milham S. Mortality in aluminum reduction plant workers. J Occup Med 1979;21:475-80.

6. Mur JM, Moulin JJ, Meyer-Bisch C, Massin N, Coulon JP, Loulergue J. Mortality of aluminum reduction plant workers in France. Int J Epidemiol 1987;16:257-64.

7. International Agency for Research on Cancer (IARC). Polynuclear aromatic compounds; part 3 (Industrial exposures in aluminium production, coal gasification, coke production and iron and steel founding). Lyon: IARC, 1984:199-293. IARC monographs on the evaluation of the carcinogenic risk of chemicals to humans, no 34 .

8. International Agency for Research on Cancer (IARC). Overall evaluations of carcinogenicity: an updating of IARC monographs, volumes 1-42. Lyon: IARC, 1987:89-91. IARC monographs on the evaluation of the carcinogenic risk of chemicals to humans, suppl 7.

9. Tremblay C, Armstrong B, Thériault G, Brodeur J. Estimation of risk of developing bladder cancer among workers exposed to coal tar pitch volatiles in the primary aluminum industry. Am J Ind Med 1995;27:335-48.

10. Armstrong B, Tremblay C, Baris D, Thériault G. Lung cancer mortality and polynuclear aromatic hydrocarbons: a casecohort study of aluminum production workers in Arvida, Quebec, Canada. Am J Epidemiol 1994;139:250-62.

11. Spinelli JJ, Band PR, Svirchev L, Gallagher RP. Mortality and cancer incidence in aluminum reduction plant workers. $\mathrm{J}$ Occup Med 1991;33:1150-5.

12. Rønneberg A, Haldorsen T, Romundstad P, Andersen A. Occupational exposure and cancer incidence among workers from an aluminum smelter in western Norway. Scand J Work Environ Health 1999;25:207-14.

13. Romundstad PR, Haldorsen T, Andersen A. Cancer incidence and cause specific mortality among workers in 2 Norwegian aluminum plants. Am J Ind Med 2000;37:175-83.

14. Romundstad $\mathrm{P}$, Haldorsen $\mathrm{T}$, Andersen A. Lung and bladder cancer among workers in a Norwegian aluminium reduction plant. Occup Environ Med 2000;57:495—9.

15. Bjørseth A, Bjørseth O, Fjeldstad PE. Polycyclic aromatic hydrocarbons in the work athmosphere: I determination in an aluminum reduction plant. Scand $\mathrm{J}$ Work Environ Health $1978 ; 4: 212-23$.

16. Romundstad PR, Haldorsen T, Rønneberg A. Exposure to $\mathrm{PAH}$ and fluoride in aluminum reduction plants in Norway: historical estimation of exposure using process parameters and industrial hygiene measurements. Am J Ind Med 1999;35:164-74.
17. Rønneberg A, Andersen A. Mortality and cancer morbidity in workers from an aluminium smelter with prebaked carbon anodes - part I exposure assessment. Occup Environ Med 1995;52:242-9.

18. Rothman KJ. Causation and causal inference. In: Schottenfeld D, Fraumeni JF Jr, editors. Cancer epidemiology and prevention. 2nd ed. New York (NY): Oxford University Press, 1996:3-10.

19. Checkoway H, Pearce N, Hickey JLS, Dement JM. Latency analysis in occupational epidemiology. Arch Environ Health 1990;45:95-100.

20. Preston DL, Lubin JH, Pierce DA, McConney ME. Epicure. Seattle (WA): Hirosoft International Corporation, 1993

21. Boffetta P, Jourenkova N, Gustavsson P. Cancer risk from occupational and environmental exposure to polycyclic aromatic hydrocarbons. Cancer Causes Control 1997;8:444-72.

22. Lindsted G, Sollenberg J. Polycyclic aromatic hydrocarbons in the occupational environment [review]. Scand J Work Environ Health 1982;8:1-19.

23. Blot WJ, Fraumeni JF Jr. Cancers of the lung and pleura. In: Schottenfeld D, Fraumeni JF Jr, editors. Cancer epidemiology and prevention, 2nd ed. New York (NY): Oxford University Press, 1996:637-55.

24. Silverman DT, Morrison AS, Devesa SS. Bladder cancer. In: Schottenfeld D, Fraumeni JF Jr, editors. Cancer epidemiology and prevention. 2nd ed. New York (NY): Oxford University Press, 1996:1156-79.

25. Grandjean P, Olsen JH, Jensen OM, Juel K. Cancer incidence and mortality in workers exposed to fluoride. JNCI 1992;84:1903-9.

26. Rønneberg A, Andersen A. Mortality and cancer morbidity in workers from an aluminium smelter with prebaked carbon anodes - part II: cancer morbidity. Occup Environ Med $1995 ; 52: 250-4$.

27. Rønneberg A, Langmark F. Epidemiologic evidence of cancer in aluminum reduction plant workers. Am J Ind Med 1992;22:573-92

28. Parkash $O$, Kiesswetter $H$. The role of urine in the etiology of cancer of the urinary bladder. Urol Int 1976;31:343-8.

29. Michaud DS, Spiegelman D, Clinton SK, Rimm EB, Curhan GC, Willet WC et al. Fluid intake and the risk of bladder cancer in men. N Engl J Med 1999;340:1390-7.

Received for publication: 23 March 2000 